\section{Essential skills for rural surgery}

To the Editor: In Chris Bateman's Izindaba article entitled 'Consciously cutting to the bone of SA's surgical/anaesthetic delivery', ${ }^{[1]} \mathrm{Dr}$ Joe Pahla is quoted as saying "It was "critical" to put together a package of basic surgical skills that could be used in district and regional hospitals.' Of the challenges faced in rural medicine, it is surgery in particular that can engender feelings of lack of confidence, incompetence and anxiety.

A common approach to strengthening preparation is to identify lists of surgical procedures that need to be performed most frequently. But that is not the same, and not as constructive, as a list of skills. It is what presents that was not on such 'lists of procedures' that can be the bigger challenge. A first and basic essential is the ingraining of the skills of using scalpel, forceps, retractors and suckers, knot-tying, making and closing incisions and control of bleeding, which may be called the 'knife, fork and spoon' skills of surgery. These are vital to avoiding uncertainty in the theatre and for being free to proceed knowingly, step by step, with another skill that I call 'procedural imprinting. Reading up on a procedure is itself an intensive exercise and a practice to be acquired. It involves bringing to the mind's eye the reality of a text and its diagrams, and a mentally rehearsed and summarised sequence of practical steps to be followed. Hamilton Bailey, Watson Jones and Harold Gillies used to be leading books on operative surgery. To take notes or even a textbook into theatre should not be embarrassing. Today there will be a variety of computer-based resources that can be used. I see the deliberate and reflective process I have outlined as an essential skill to be taught and practised. I have summarised here what I published in 2003 , based on 18 years of practising surgery at a former mission hospital in Transkei. ${ }^{[2]}$

\section{Ronald F Ingle}

Hillcrest, KwaZulu-Natal, South Africa (retired)

inglerf@iafrica.com 1. Bateman C. Consciously cutting to the bone of SA's surgical/anaesthetic delivery. S Afr Med J
2016;106(2):132-134. DOI:10.7196/SAMJ.2016.v106i2.10526

2. Ingle R. Preparing for rural surgery: Procedures or skills? S Afr Fam Pract 2003;45(9):7-8.

S Afr Med J 2016;106(6):535. DOI:10.7196/SAMJ.2016v106i6.10720 